\title{
Application of an ultrasonic tomographic technique for detecting defects in standing trees
}

\author{
Cheng-Jung Lin ${ }^{\mathrm{a}}$, Yu-Chien Kao ${ }^{\mathrm{b}}$, Ta-Te Lin ${ }^{\mathrm{c}}$, Ming-Jer Tsai ${ }^{\mathrm{b}, *}$, \\ Song-Yung Wang ${ }^{b}$, Lang-Dong Lin ${ }^{\mathrm{d}}$, Ya-Nan Wang ${ }^{\mathrm{b}}$, Ming-Hsun Chan ${ }^{\mathrm{e}}$ \\ a Division of Forest Utilization, Taiwan Forestry Research Institute, Taipei, Taiwan \\ ${ }^{\mathrm{b}}$ School of Forestry and Resource Conservation, College of Bio-Resources and Agriculture, National Taiwan University, Taipei, Taiwan \\ ${ }^{\mathrm{c}}$ Department of Bio-Industrial Mechatronics Engineering, National Taiwan University, Taipei, Taiwan \\ ${ }^{\mathrm{d}}$ Department of Forest Products Science, National Chiayi University, Chiayi, Taiwan \\ ${ }^{\mathrm{e}}$ The Experimental Forest, College of Bio-Resources and Agriculture, National Taiwan University, Nan-Tou, Taiwan
}

\section{A R T I C L E I N F O}

\section{Article history:}

Received 20 July 2007

Received in revised form

27 September 2007

Accepted 27 September 2007

Available online 24 June 2008

\section{Keywords:}

Ultrasonic tomographic technique

Defect detection

Trees

\begin{abstract}
A B S T R A C T
The purpose of this study was to evaluate defects in trees using an ultrasonic tomographic technique. In order to simulate different degrees and kinds of defects, a hole was chiseled in the central and side areas of trunk cross-sections and then the ultrasonic velocities were measured in multiple directions (eight equidistant ultrasonic test points and 56 independent travel time measurements) and analyzed using ultrasonic equipment. Results revealed that the highest coefficient of determination was found between the residual disc diameter ratio and the ultrasonic velocity in the virtual radial direction. Strong correlations between the drop in the relative ultrasonic velocity and residual disc diameter ratio were observed in the virtual radial direction. Moreover, the ratio of ultrasonic velocity along paths $\mathrm{D}$ (a threepoint interval between two measured points) to B (a one-point interval between two measured points) decreased with increase in the ratio of the hole-to-disc area. However, values became more diverse for specimens with a hole chiseled in the side area as the ratio of the hole-to-disc area increased. In situ experimental results showed that differences in the mapped colors and ultrasonic velocities between the hole area and its surrounding area were obvious, and when the ratio of the hole area to the crosssectional area exceeded $2.8 \%$, the hole was detectable by ultrasonic tomography. Therefore, the location and size of the hole in the tree trunk cross-section could be detected by this ultrasonic tomographic technique.
\end{abstract}

(c) 2008 Elsevier Ltd. All rights reserved.

\section{Introduction}

Detecting deterioration in trees, particularly internal decay that does not have external indicators, is an important issue for forest management. Various nondestructive evaluation (NDE) techniques, based on different concepts, have been used to detect deterioration in trees in order to identify hazardous trees, to prevent the spread of decay, and to improve stand conditions. Sounding a tree by striking it with a tool can be used to detect advanced decay or hollows inside the trunk, but this method is not effective on large trees with thick bark (McCracken, 1985). Visual tree assessments are successfully supported by stress wave and ultrasonic wavebased evaluations. Stress and ultrasonic wave transmission times or attenuation in wood have proven to be effective parameters for detecting and estimating deterioration in tree stems and wood structural members (Hoyle and Pellerin, 1978; Hoyle and

\footnotetext{
* Corresponding author. Tel.: +8862 33664 641; fax: +8862 23686335 .

E-mail address: tmj@ntu.edu.tw (M.-J. Tsai).
}

Rutherford, 1987; Mattheck and Bethge, 1993; Ross and Pellerin, 1994; Yamamoto et al., 1998; Lin et al., 2000; Pellerin and Ross, 2002). However, the one-dimensional stress wave test provides limited information about defects in trees. Reliable defect evaluation for imaging internal characteristics in logs and trees is possible by X-ray and neutron radiography, computed tomography (CT), and magnetic resonance (MR) (Habermehl et al., 1986; Hailey and Morris, 1987; Holoyen and Birkeland, 1987; Wagner et al., 1989; Oja et al., 2000). These techniques can provide one- to three-dimensional spatial locations of various defects and internal wood characteristics, but their application to trees has been limited because of the high costs, fear of X-rays and gamma rays, strong regulations, and the control of radiation sources associated with their use.

Some NDE techniques have recently been developed for tomographic investigations. Tomography allows the reconstruction of a cross-section through an object by means of measurements performed on the object surface and by measuring the energy that passes through the object itself (Worthington, 1984; Nolet, 1987; 
Stewart, 1991). Ultrasonic tomography was applied by Tomikawa et al. (1990) and Biagi et al. (1994) to investigate poles and timber and by Comino et al. (2000) on living trees; Rust and Göcke (2000) applied sonic tomography to trees. Ultrasonic tomography allows the user to reconstruct the distribution of the velocity of the ultrasonic wave as it propagates within the investigated section. Because the ultrasonic velocity $(V)$ is related to the density $(\rho)$ and dynamic modulus of elasticity (DMOE; DMOE $\left.=V^{2} \times \rho\right)$, decreasing the velocity could, for instance, be diagnostic of fungal degradation of cell walls (Bucur, 1995). Furthermore, the ultrasonic velocity has been demonstrated to be very sensitive in the early stage of wood degradation (Wilcox, 1988; Bauer et al., 1991).

The purpose of this study was to investigate the location and area of a defect in standing trees using ultrasonic tomography. Ten discs and three decayed Japanese cedar trees were examined with an ultrasonic instrument (Sylvatest, Swiss Products) and Arbotom 2D software (Rinn Tech, Germany). The interrelationships among the residual disc diameter ratio, the ratio of the defect-to-disc area (tree defect parameters), the ultrasonic velocity, and the drop in the relative ultrasonic velocity (NDE parameters) were examined and analyzed.

\section{Materials and methods}

\subsection{Test materials}

Ten circular cross-sectional discs (30-35 cm in diameter and $10 \mathrm{~cm}$ thick) of sound Japanese cedar (Cryptomeria japonica) were prepared for this study. To prevent the occurrence of defects during the drying process, the tested discs were kept wet. Multiple ultrasonic measurements were performed after chiseling a circular hole (an artificial defect) in the specimens. The shapes and sizes of chiseled holes were divided into two kinds, as shown in Fig. 1. For discs chiseled in the central area,
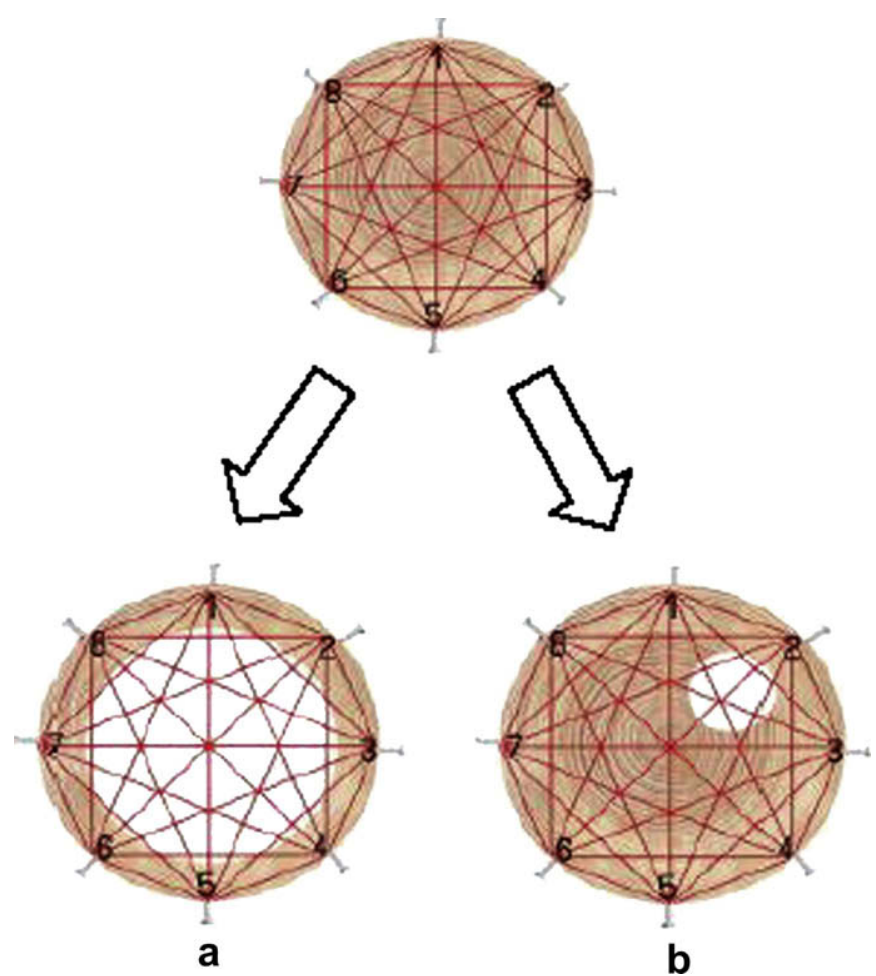

Fig. 1. Eight equidistant ultrasonic test points and 56 independent travel time measurements for each investigated section after a hole was chiseled in the central or side area. The ultrasonic probe was sequentially located at points $1,2,3,4,5,6,7$, and 8 . Upper, unblemished disc. Lower, disc with an artificial hole. (a) A hole was chiseled in the central area of a trunk cross-section; the circular hole was gradually widened from 1 to $23 \mathrm{~cm}$ in diameter at an interval of $2 \mathrm{~cm}$. (b) A hole was chiseled in the side area of a trunk cross-section; the circular hole was gradually widened in the center of quarterdivided discs from 1 to $10 \mathrm{~cm}$ in diameter at an interval of $1 \mathrm{~cm}$. the circular hole was gradually enlarged with a chisel from 1 to $23 \mathrm{~cm}$ in diameter at $2-\mathrm{cm}$ intervals. For discs chiseled in the side area, the circular hole was gradually enlarged with a chisel in the center of a quarter-divided disc from 1 to $10 \mathrm{~cm}$ in diameter at $1-\mathrm{cm}$ intervals.

The experiments were carried out in situ on three Japanese cedar trees that were decayed and going to be cut down. The trees selected in this study were located in the no. 173 plot, third branch station, Chi-Tou working station of the Experimental Forest of National Taiwan University. Multiple ultrasonic measurements on three trees, referred to as trees A, B, and C, were made on the trunk sections $130 \mathrm{~cm}$ from ground level (breast height). After the field tests were performed, the trees were cut down, and one cross-sectional disc ( $10 \mathrm{~cm}$ thick) was cut from each sample tree at or near the abovementioned height, extracted, put in a plastic bag, and stored in a refrigerator at $5^{\circ} \mathrm{C}$. Within $24 \mathrm{~h}$, measurements were performed on the three discs in the laboratory in order to compare the results with those obtained directly on the live trees.

\subsection{Ultrasonic tomography}

The ultrasonic equipment used for data acquisition was a Sylvatest (frequency, $22 \mathrm{kHz}$; Swiss Products). An electric signal is transformed by the transmitter probe into an ultrasonic pulse that travels through the wood, is received by the receiver probe, and is again transformed into an electric signal that can be properly amplified and visualized, allowing for travel time measurements (Sandoz et al., 2000).

The multiple ultrasonic measurements on the wood discs and tree trunks were carried out on eight equidistant points around the circumference of the tree. Specially made stainless steel nails were driven into the xylem of each sample disc and tree (Fig. 1). Their positions in the trees were about $130 \mathrm{~cm}$ above the ground with an angle of $90^{\circ}$ between the nails and the trunk axis for connecting the transducer to detect the propagated ultrasonic wave. The transmitter probe was located at point 1 , and the ultrasonic pulse was acquired by the receiver probe at all the other points; then the transmitter was moved to point 2 . The measurements were repeated for all the other positions of the transmitter probe, allowing for 56 independent propagation time measurements for each investigated section.

\subsection{Data processing}

\subsubsection{Ultrasonic velocity, residual disc diameter ratio, and drop in the relative} ultrasonic velocity

According to the positions of two measured ultrasonic test points, four types of ultrasonic travel routes in the discs were first divided into path A (two measured points adjacent to each other, such as from point 1 to 2 ), path $B$ (with a one-point interval between two measured points, such as from point 1 to 3 ), path $C$ (with a two-point interval between two measured points, such as from point 1 to 4 ), and path $\mathrm{D}$ (virtual radial direction, with a three-point interval between two measured points, such as from point 1 to 5 ). The ultrasonic velocity, residual disc diameter ratio, and drop in the relative ultrasonic velocity were then estimated by the following formulae

$V=D / t$

$\mathrm{RR}=(R-d) / R$,

and

$R V D(\%)=100\left(V_{\text {reference }}-V_{\text {measured }}\right) / V_{\text {reference }}$

where $V$ is the ultrasonic velocity, $D$ is the distance between the two transducers, $t$ is the propagation time of the pulse from the transmitting transducer to the receiving transducer, RR is the residual disc diameter ratio, $R$ is the disc diameter, $d$ is the hole diameter, RVD (\%) is the drop in the relative ultrasonic velocity, $V_{\text {reference }}$ is the ultrasonic velocity between test points before chiseling, and $V_{\text {measured }}$ is the ultrasonic velocity between test points after chiseling.

\subsubsection{Ratio of ultrasonic velocity along paths $D-B\left(\mathrm{~V}_{\text {path } D} / \mathrm{V}_{\text {path } B}\right)$ and ratio of the} hole-to-disc area

In order to understand the effects of ultrasonic parameters on the hole area and position, the ratio of ultrasonic velocity along paths $\mathrm{D}-\mathrm{B}\left(V_{\text {path } \mathrm{D}} / V_{\text {path } \mathrm{B}}\right)$, and the ratio of the hole-to-disc area were calculated by the following formulae

$\mathrm{RV}=V_{\text {path } \mathrm{D}} / V_{\text {path } \mathrm{B}}$,

and

$\mathrm{HD}=\pi(d / 2)^{2} / \pi(R / 2)^{2}$

where RV is the ratio of the ultrasonic velocity along paths D-B, $V_{\text {path } \mathrm{D}}$ is the ultrasonic velocity obtained from path $\mathrm{D}, V_{\text {path }} \mathrm{B}$ is the ultrasonic velocity obtained from path $\mathrm{B}, \mathrm{HD}$ is the ratio of the hole-to-disc area, $d$ is the hole diameter, and $R$ is the disc diameter. 


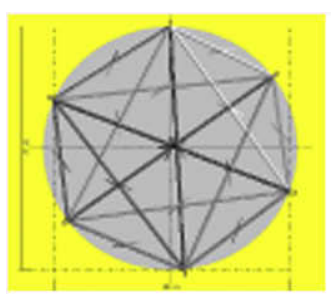

a

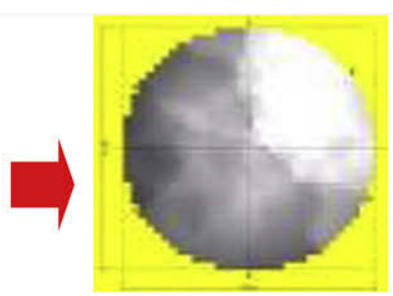

b

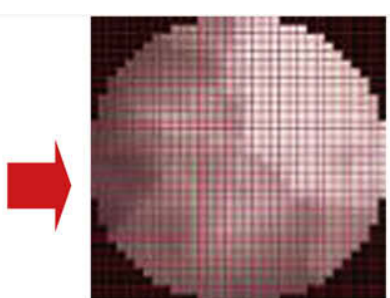

C

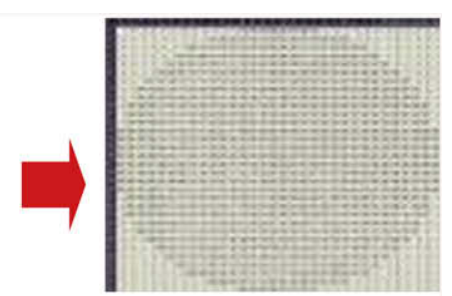

d

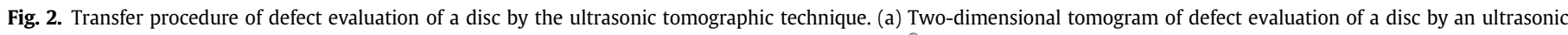

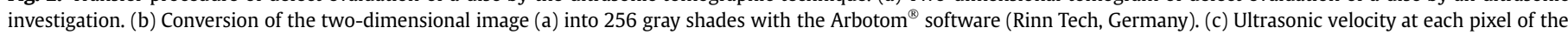
tomogram calculated by the custom-made software developed in this study using Borland C++ builder. (d) Tomogram file exported to Microsoft Excel for further assessment.

2.3.3. Conversion of the color image to grayscale and ultrasonic velocity values

In order to evaluate the shapes and sizes of tree defects, two-dimensional image tomographic software (Arbotom ${ }^{\circledR}$ software) developed by Rinn Tech (Germany) was used. Tree defect tomograms in different colors, indicating various ultrasonic velocities, obtained from the Arbotom ${ }^{\circledR}$ software, could be converted into 256 gray shades. The Arbotom ${ }^{\circledR}$ software uses a two-step filter to select just the best values from the measurements to provide the optimum quality. The values in the tomogram are weighted in contrast to the values in the velocity table that resulted from ultrasonic measurements in our study. The Arbotom ${ }^{\circledR}$ software takes differences of axial, radial, and tangential velocities into account and standardizes them. In the surface graph the values are additionally weighted by parameters affected by tree species (Anon, 2005). The ultrasonic velocity at each pixel of the tomogram could be further calculated by the custom-made software developed in this study using

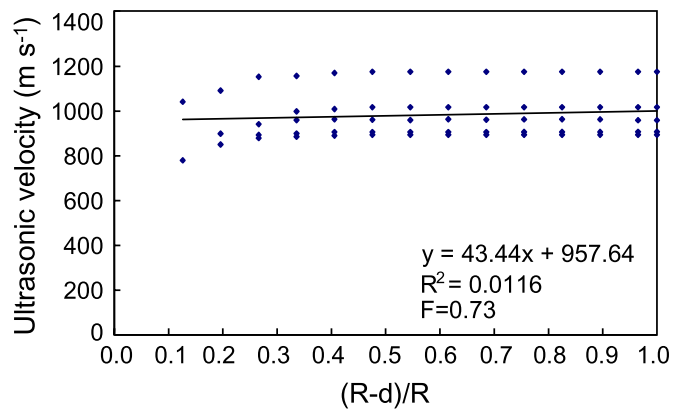

Path A

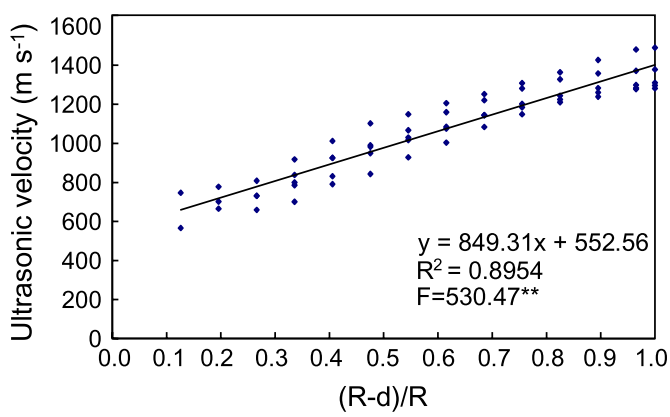

Path C

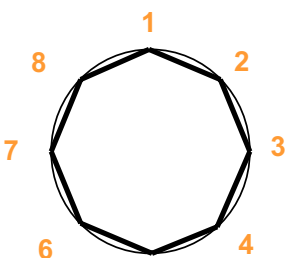

5

Path A

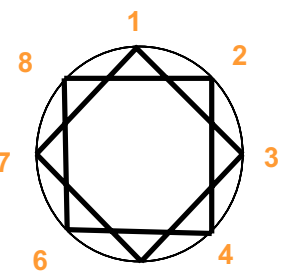

Path B

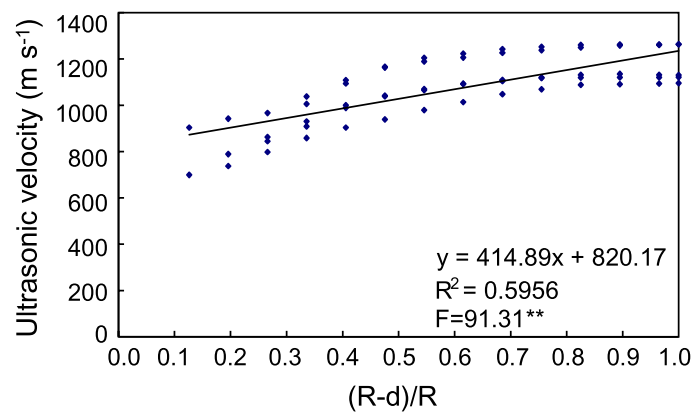

Path B

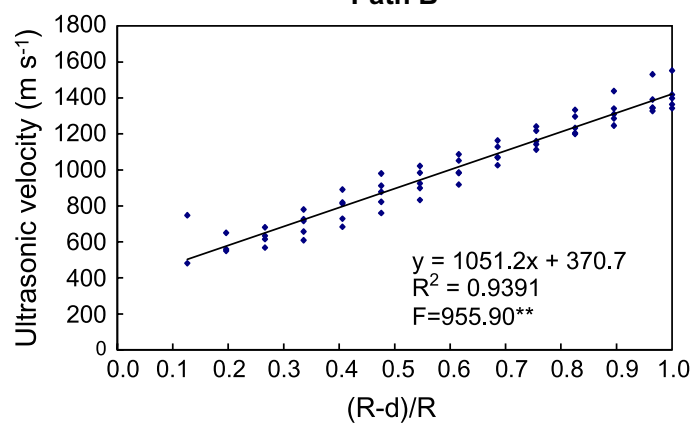

Path D

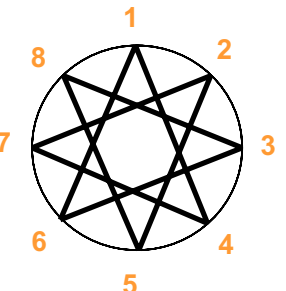

Path C

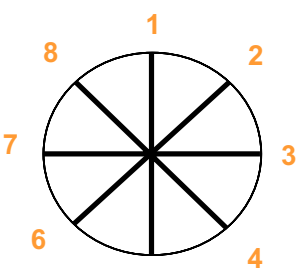

5

Path D

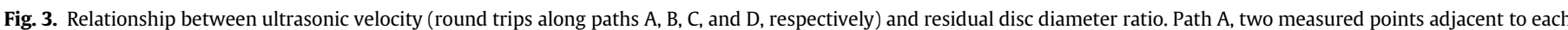

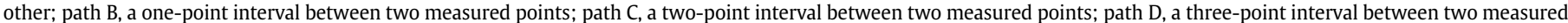
points. 

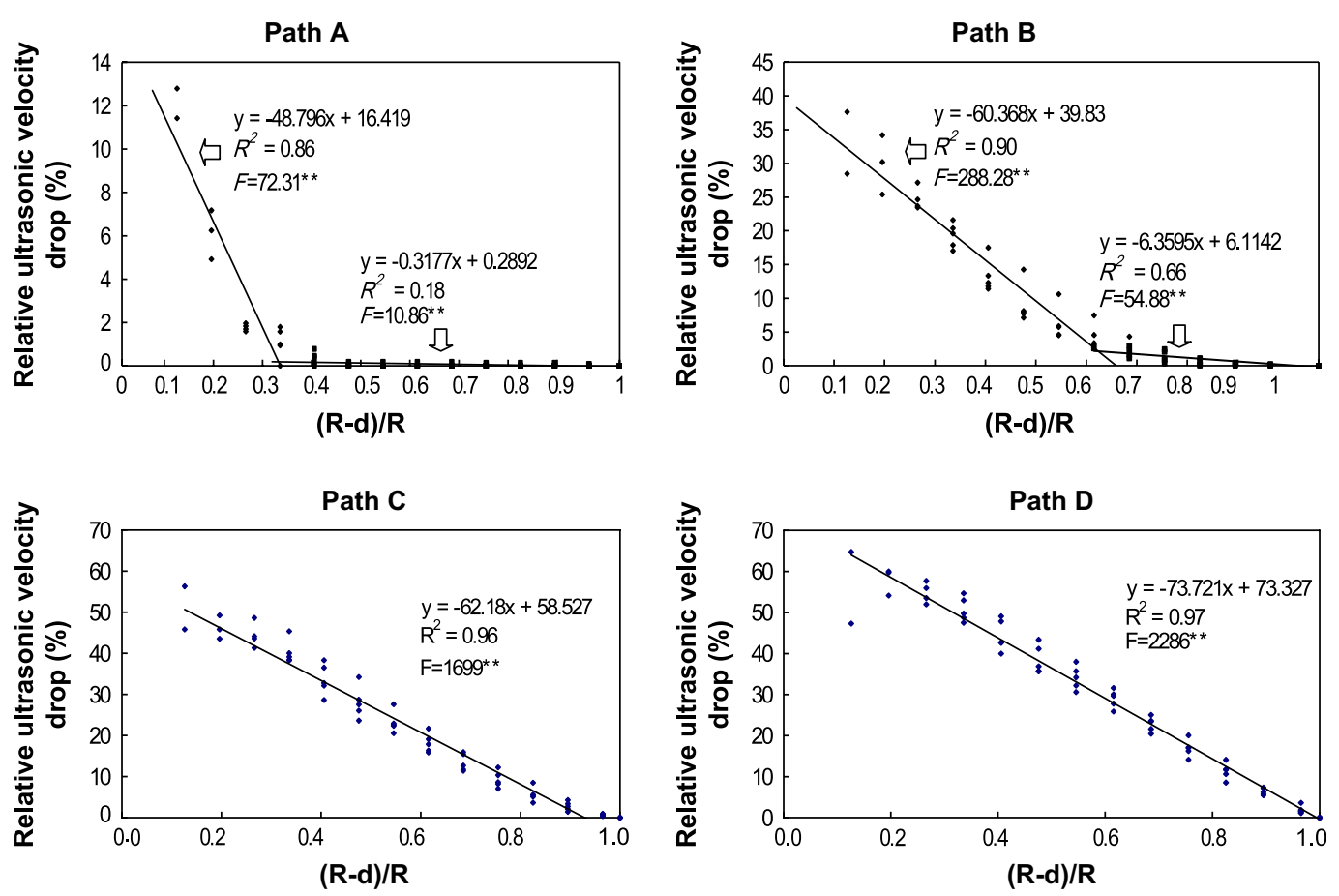

Fig. 4. Relationship between the drop in the relative ultrasonic velocity and the residual disc diameter ratio. For paths A, B, C, and D, see Fig. 3 .

the residual disc diameter ratio and the ultrasonic velocity along path $\mathrm{D}$, whose $r^{2}$ value was about 0.94 , followed in order according to $r^{2}$ values by paths $\mathrm{C}, \mathrm{B}$, and $\mathrm{A}$. For paths $\mathrm{A}$ and $\mathrm{B}$, the ultrasonic velocity was not influenced when the residual disc diameter ratio was more than about 0.3 and 0.6 , respectively. In comparison with paths $A$ and $B$, the multiple measurements of the ultrasonic velocity along paths $\mathrm{C}$ and $\mathrm{D}$ were more feasible for detecting defects in the discs. This is because the ultrasonic travel route in wood is the fastest one, not the shortest one. Ross and Pellerin (1994) indicated that the ultrasonic velocity in the radial direction was higher than that in the tangential direction. In the near tangential direction, such as path $B$, the propagation of the ultrasonic wave declines toward the receiver probe. As a result, the ultrasonic velocity was lower, even though there was no hole (defect) in the wood.

In this study, a change in the ultrasonic velocity along paths $\mathrm{C}$ and $\mathrm{D}$ was observed when the residual disc diameter ratio was 0.95 (i.e., a hole diameter of $3 \mathrm{~cm}$ ). The reason is that a small hole

Table 1

Correlations between the ratio of ultrasonic velocity along paths $\mathrm{D}-\mathrm{B}\left(V_{\text {path } \mathrm{D}} / V_{\text {path B }}\right)$ and the ratio of the hole-to-disc area (HD), analyzed by linear regression $(Y=A X+B)$ formulae for detecting a defect in the central section area

\begin{tabular}{lllll}
\hline \multicolumn{2}{l}{ Linear regression model $Y=A X+B$} & & $r^{2}$ \\
\hline$Y$ & $X$ & $A$ & $B$ & \\
\hline$V_{1-5} / V_{2-8}$ & HD & -1.06 & 1.14 & $0.87^{*}$ \\
$V_{2-6} / V_{1-3}$ & HD & -0.91 & 1.09 & $0.84^{*}$ \\
$V_{3-7} / V_{2-4}$ & HD & -0.98 & 1.10 & $0.89^{*}$ \\
$V_{4-8} / V_{3-5}$ & HD & -0.91 & 1.10 & $0.85^{*}$ \\
$V_{5-1} / V_{4-6}$ & HD & -0.99 & 1.10 & $0.85^{*}$ \\
$V_{6-2} / V_{5-7}$ & HD & -0.98 & 1.09 & $0.85^{*}$ \\
$V_{7-3} / V_{6-8}$ & HD & -1.01 & 1.11 & $0.88^{*}$ \\
$V_{8-4} / V_{7-1}$ & HD & -0.92 & 1.10 & $0.86^{*}$ \\
Combined & HD & -0.97 & 1.10 & $0.85^{*}$
\end{tabular}

Where: $V_{\text {path } \mathrm{D}} / V_{\text {path B }}$ is the ratio of the ultrasonic velocity along paths D-B; ultrasonic velocity of path $\mathrm{D}\left(V_{\text {path }} \mathrm{D}\right)$, is from probe $1-5\left(V_{1-5}\right)$, probe $2-6\left(V_{2-6}\right)$, probe 3-7 $\left(V_{3-7}\right)$, probe 4-8 $\left(V_{4-8}\right)$, probe 5-1 $\left(V_{5-1}\right)$, probe $6-2\left(V_{6-2}\right)$, probe $7-3\left(V_{7-3}\right)$, and probe 8-4 $\left(V_{8-4}\right)$; ultrasonic velocity of path $\mathrm{B}\left(V_{\text {path B }}\right)$, is from probe $2-8\left(V_{2-8}\right)$, probe $1-3\left(V_{1-3}\right)$, probe $2-4\left(V_{2-4}\right)$, probe $3-5\left(V_{3-5}\right)$, probe $4-6\left(V_{4-6}\right)$, probe 5-7 $\left(V_{5-7}\right)$, probe $6-8\left(V_{6-8}\right)$, and probe $7-1\left(V_{7-1}\right)$.

${ }^{*}$ Significant difference at $p<0.01$. diameter influenced paths $C$ and $D$. In this experiment, the velocity change of paths A, B, C, and D was about $100-150 \mathrm{~ms}^{-1}$. Comparing the velocity change obtained with the velocity determination error, it was found that the velocity change was smaller than two times of velocity determination error.

\subsection{Effects of the residual disc diameter ratio on the drop in the relative ultrasonic velocity}

The relationships between the drop in the relative ultrasonic velocity and residual disc diameter ratio are shown in Fig. 4. Two linear regression models were found between the residual disc diameter ratio and the drop in the relative ultrasonic velocity along paths $A$ and $B$. The intersecting points of the two regression equations were 0.33 for path $A$ and 0.63 for path $B$. This suggests that the drop in the relative ultrasonic velocity was significantly

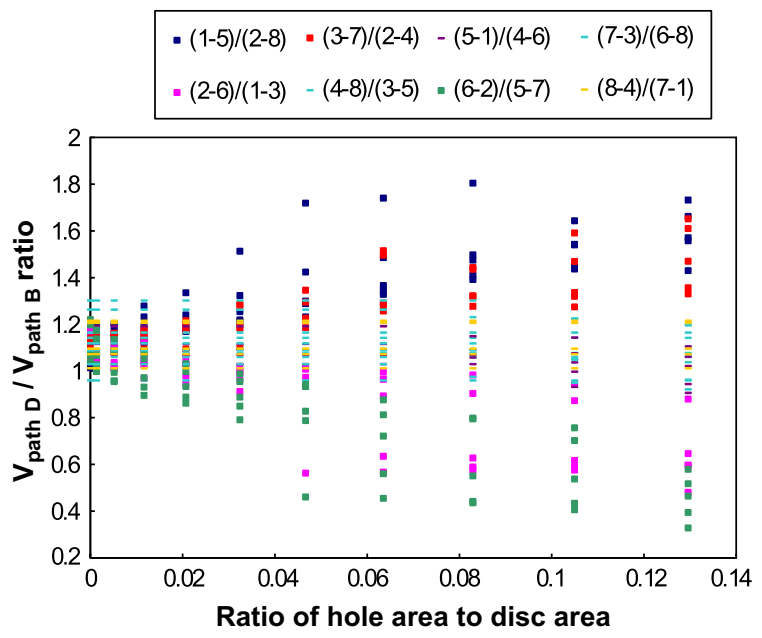

Fig. 5. Relationship between the ratio of ultrasonic velocity along paths D-B $\left(V_{\text {path }} \mathrm{D} /\right.$ $\left.V_{\text {path B }}\right)$ and the ratio of the hole area to disc area for detecting a defect in the side area. For $V_{\text {path } \mathrm{D}} / V_{\text {path B }}$, see Table 1. 


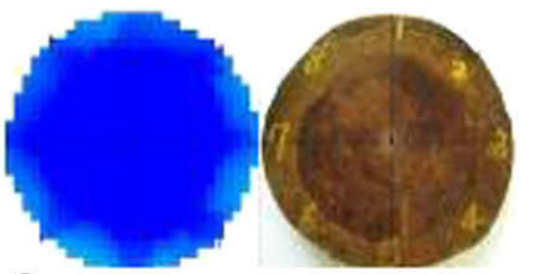

a

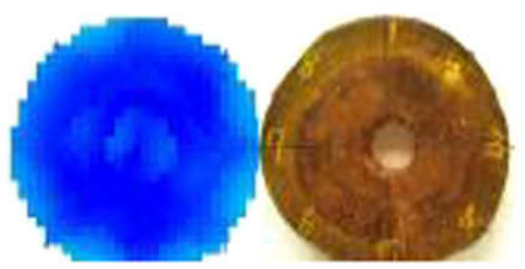

d
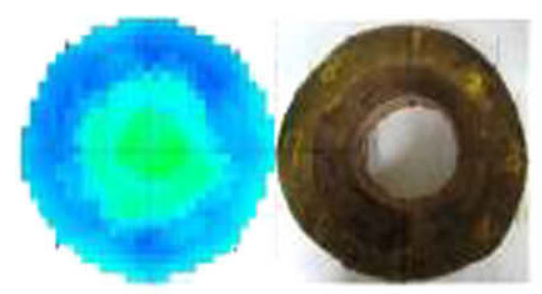

g

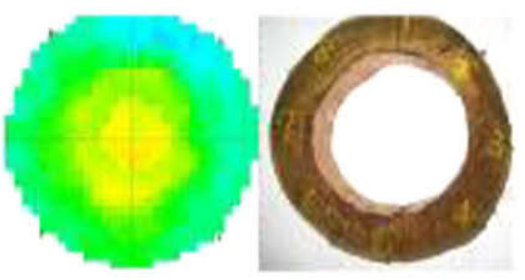

j

$19 \mathrm{~cm}$

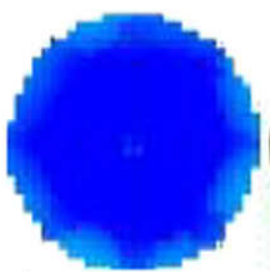

b

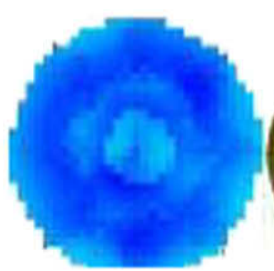

e

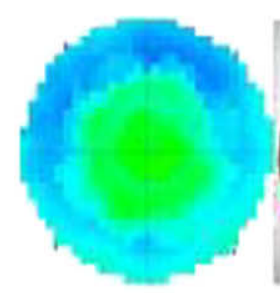

$9 \mathrm{~cm}$

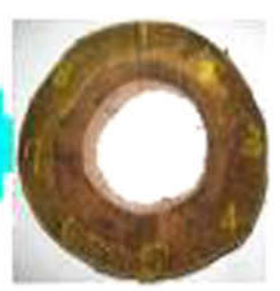

h

$15 \mathrm{~cm}$

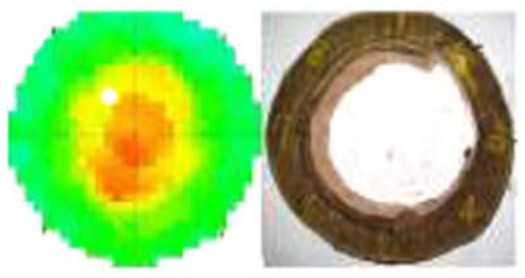

k

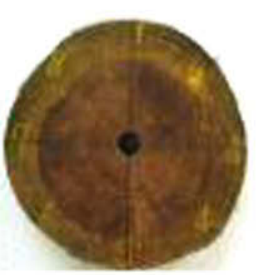

$3 \mathrm{~cm}$

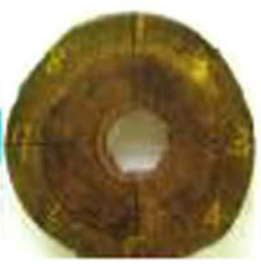

m

$21 \mathrm{~cm}$
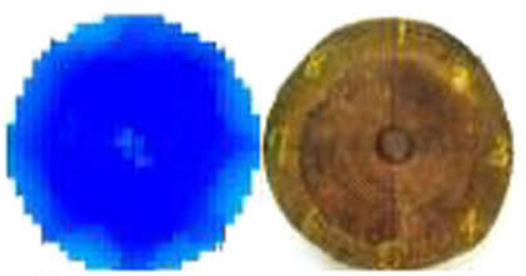

$5 \mathrm{~cm}$

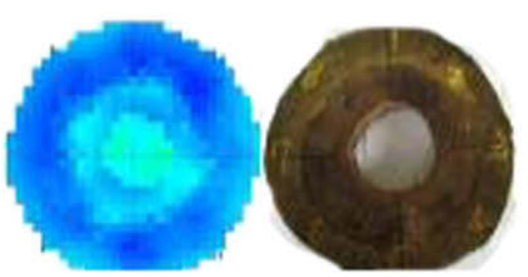

$11 \mathrm{~cm}$

f
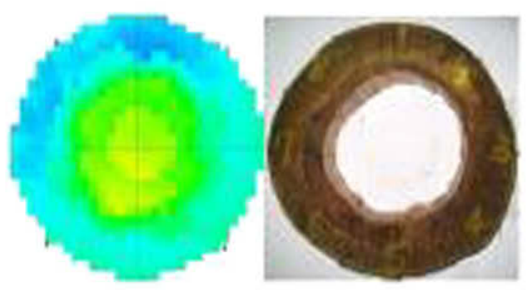

i

$17 \mathrm{~cm}$

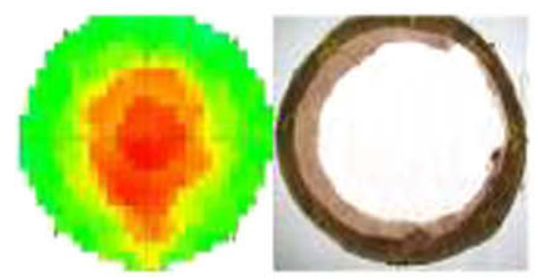

$23 \mathrm{~cm}$

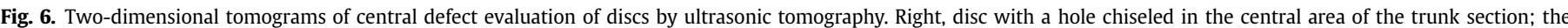
circular hole was gradually enlarged from 1 to $23 \mathrm{~cm}$ in diameter at an interval of $2 \mathrm{~cm}$; left, corresponding ultrasonic tomogram.

influenced on paths $A$ and $B$ when the residual disc diameter ratios were less than 0.33 and 0.63 , respectively.

In this study, strong correlations between the drop in the relative ultrasonic velocity and residual disc diameter ratio were observed on paths $C$ and $D$, whose $r^{2}$ values were 0.96 and 0.97 , respectively. This observation of strong correlations allowed us to conclude that the drop in the relative ultrasonic velocity along paths $C$ and $D$ was a better method for evaluating defects occurring in the central area of a tree section.

\subsection{Effects of the ratio of ultrasonic velocity along paths $D-B$ on the hole area and position}

The relationships between the ratio of ultrasonic velocity along paths D-B ( $\left.V_{\text {path } \mathrm{D}} / V_{\text {path B }}\right)$ and the ratio of the hole-to-disc area, analyzed by linear regression $(Y=A X+B)$ formulae for a defect in the central area, are shown in Table 1 . The $V_{\text {path } \mathrm{D} / V_{\text {path } \mathrm{B}} \text { values }}$ decreased with an increase in the ratio of the hole-to-disc area. Their relationships can be represented by negative linear regression formulae, and it was found that the coefficient of determination $\left(r^{2}\right)$ values were $0.84-0.89$. This suggests that the $V_{\text {path }}$ $\mathrm{D} / V_{\text {path в }}$ ratio could be used as an index for assessing the defect position and dimension in trees in this study.
The relationships between $V_{\text {path } \mathrm{D}} / V_{\text {path в }}$ and the ratio of the hole-to-disc area for defect detection in the side area are plotted in Fig. 5. The $V_{\text {path } \mathrm{D}} / V_{\text {path B }}$ values became more diverse as the ratio of hole-to-disc area increased. The $V_{\text {path } \mathrm{D}} / V_{\text {path в }}$ values were 1.0-1.2 when in an unholed state. However, the $V_{\text {path } \mathrm{D}} / V_{\text {path B }}$ values were 0.8-1.4 and 0.3-1.8, when the hole diameters were 5 and $10 \mathrm{~cm}$, respectively. It was also found that the values of $V_{1-5} / V_{2-8}$ and $V_{3-7} /$ $V_{2-4}$ increased with increase in the ratio of the hole-to-disc area. Their relationships can be represented by positive linear regression formulae $\left(r^{2}=0.67-0.71\right)$. On the contrary, the values of $V_{2-6} / V_{1-3}$ and $V_{6-2} / V_{5-7}$ decreased with an increase in the hole/section area

\section{Table 2}

Correlations among ultrasonic velocity obtained from ultrasonic tomography, the ratio of the hole-to-disc diameter $(\mathrm{RH})$, the residual disc diameter ratio (RR), and the ratio of the hole-to-disc area (HD), analyzed by linear regression $(Y=A X+B)$ formulae for detecting a defect in the central section area

\begin{tabular}{llrrrrr}
\hline Linear regression model $Y=A X+B$ & & & \multirow{2}{*}{$r^{2}$} & $F$ values \\
\cline { 1 - 4 }$Y$ & $X$ & \multicolumn{1}{l}{$A$} & \multicolumn{1}{c}{$B$} & & \\
\hline Ultrasonic velocity obtained & RH & -575.08 & 1516.6 & 0.72 & $162^{*}$ \\
from ultrasonic tomography & RR & 559.05 & 956.3 & 0.72 & $160^{*}$ \\
& HD & -794.96 & 1451.2 & 0.76 & $200^{*}$ \\
\hline
\end{tabular}

* Significant difference at $p<0.01$. 

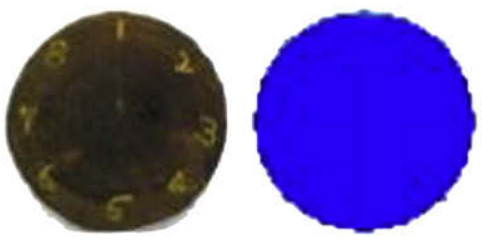

$0 \mathrm{~cm}$
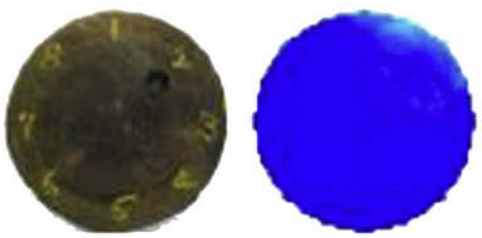

d

$3 \mathrm{~cm}$
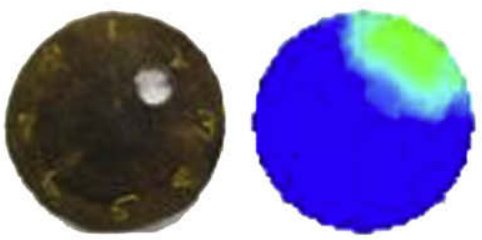

g

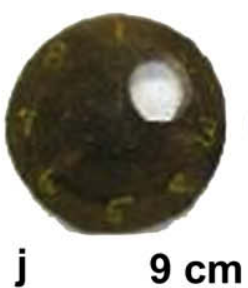

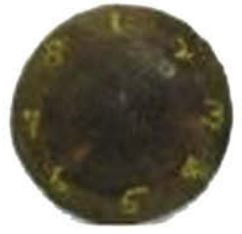

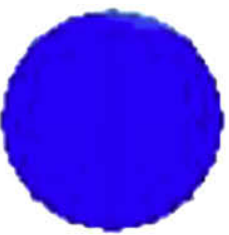

$1 \mathrm{~cm}$
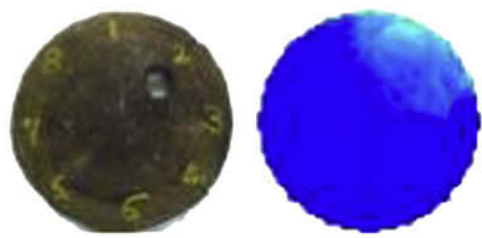

e

$4 \mathrm{~cm}$
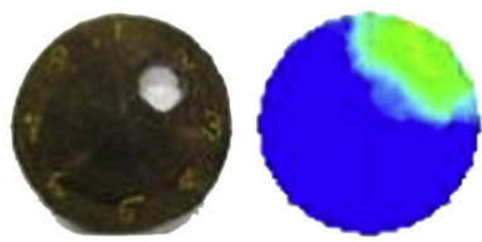

h

$7 \mathrm{~cm}$
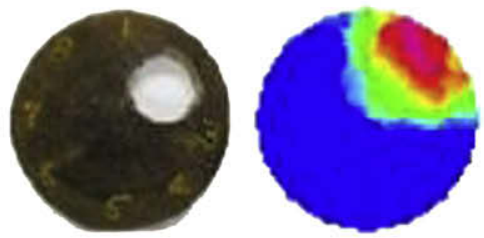

k
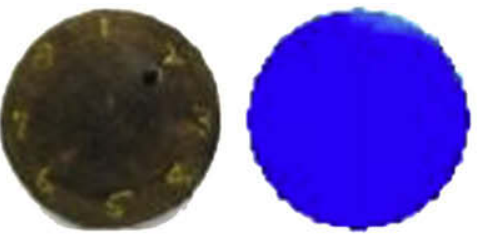

C

$2 \mathrm{~cm}$
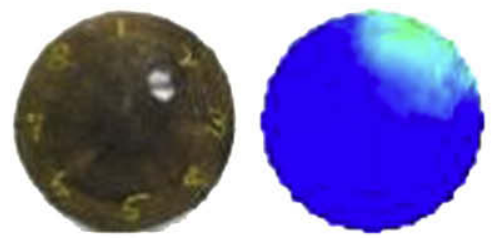

f

$5 \mathrm{~cm}$
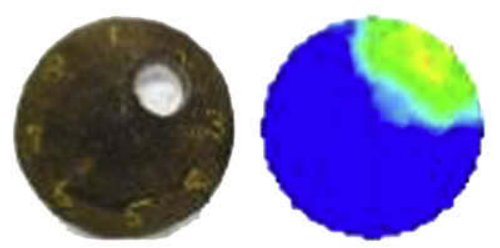

i

$8 \mathrm{~cm}$

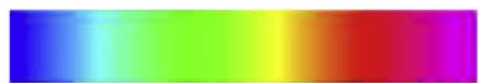

$1900 \mathrm{~m} \mathrm{~s}^{-1}$

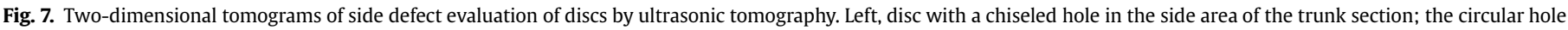
was gradually enlarged in the center of a quarter-divided disc from 1 to $10 \mathrm{~cm}$ in diameter at an interval of $1 \mathrm{~cm}$; right, corresponding ultrasonic tomogram.

ratios. Their relationships can be represented by negative linear regression formulae $\left(r^{2}=0.64-0.70\right)$. This means that the ultrasonic velocity decreased when the ultrasonic propagation route approached a defect in a tree section. Therefore, these evaluation parameters $\left(V_{1-5} / V_{2-8}, V_{3-7} / V_{2-4}, V_{2-6} / V_{1-3}\right.$, and $\left.V_{6-2} / V_{5-7}\right)$ could be used as an index for assessing the defect position in transverse section of tree.

\subsection{Relationships among ultrasonic velocity obtained from} ultrasonic tomography, the ratio of the hole-to-disc diameter, the residual disc diameter ratio, and the ratio of the hole-to-disc area

Two-dimensional tomograms for evaluating a central defect in wood discs by ultrasonic tomography are shown in Fig. 6. More blue on the tomogram indicates a higher ultrasonic velocity. The highest ultrasonic velocity was $1600 \mathrm{~ms}^{-1}$. On the contrary, more pink on the tomogram indicates a lower ultrasonic velocity. The lowest

\section{Table 3}

Correlations among the ultrasonic velocity obtained from ultrasonic tomography, the ratio of the hole-to-disc diameter $(\mathrm{RH})$, and the ratio of the hole-to-disc area (HD), analyzed by linear regression $(Y=A X+B)$ formulae for detecting a defect in the side section area

\begin{tabular}{|c|c|c|c|c|c|}
\hline \multicolumn{4}{|l|}{ Linear regression model $Y=A X+B$} & \multirow[t]{2}{*}{$r^{2}$} & \multirow[t]{2}{*}{$F$ values } \\
\hline$Y$ & $X$ & $A$ & $B$ & & \\
\hline $\begin{array}{l}\text { Ultrasonic velocity obtained } \\
\text { from ultrasonic tomography }\end{array}$ & $\begin{array}{l}\mathrm{RH} \\
\mathrm{HD}\end{array}$ & $\begin{array}{l}-321.1 \\
-942.9\end{array}$ & $\begin{array}{l}2091.5 \\
2074.6\end{array}$ & $\begin{array}{l}0.96 \\
0.99\end{array}$ & $\begin{array}{l}120,557^{*} \\
851,663^{*}\end{array}$ \\
\hline
\end{tabular}

*Significant difference at $p<0.01$. ultrasonic velocity was $600 \mathrm{~ms}^{-1}$. As shown in Fig. 6, the color of the tomograms gradually changed from blue to pink as the hole was gradually enlarged from 1 to $23 \mathrm{~cm}$ in diameter at 2-cm intervals. Color differences between the central area and its surrounding area were detectable when the hole diameter was $5 \mathrm{~cm}$ (the ratio of the hole-to-disc area was $2.8 \%$ ). This finding is similar to that by Divos and Divos (2005). They found the resolution of the acoustic tomographic system is $2.5 \%$ (with eight channels, velocity difference is $100 \mathrm{~ms}^{-1}$ ). In this study, two-dimensional tomograms for evaluating a central defect in wood discs by ultrasonic tomography also revealed that a slight blue area in the central area of the disc was observed with a hole diameter of $9 \mathrm{~cm}$. The color of the tomograms turned green when the hole diameter was $11 \mathrm{~cm}$. The green color area became bigger until the color turned to red with a hole diameter of $21 \mathrm{~cm}$.

In order to further evaluate the defect, the two-dimensional tomograms were first converted into 256 gray shades using the Arbotom $^{\circledR}$ software. The ultrasonic velocity at each pixel of the tomogram was then calculated using our custom-made program, based on the linear relationship between the grayscale value and the ultrasonic velocity, and exported to a Microsoft Excel file for further analyses. Table 2 reveals the correlations among ultrasonic velocity obtained from ultrasonic tomography, the ratio of the holeto-disc diameter, the residual disc diameter ratio, and the ratio of the hole-to-disc area, analyzed by linear regression $(Y=A X+B)$ formulae for detecting a defect in the central section area. These results were significant at the 0.01 confidence level, and the $r^{2}$ values of the regression analysis were $0.72-0.76$. 


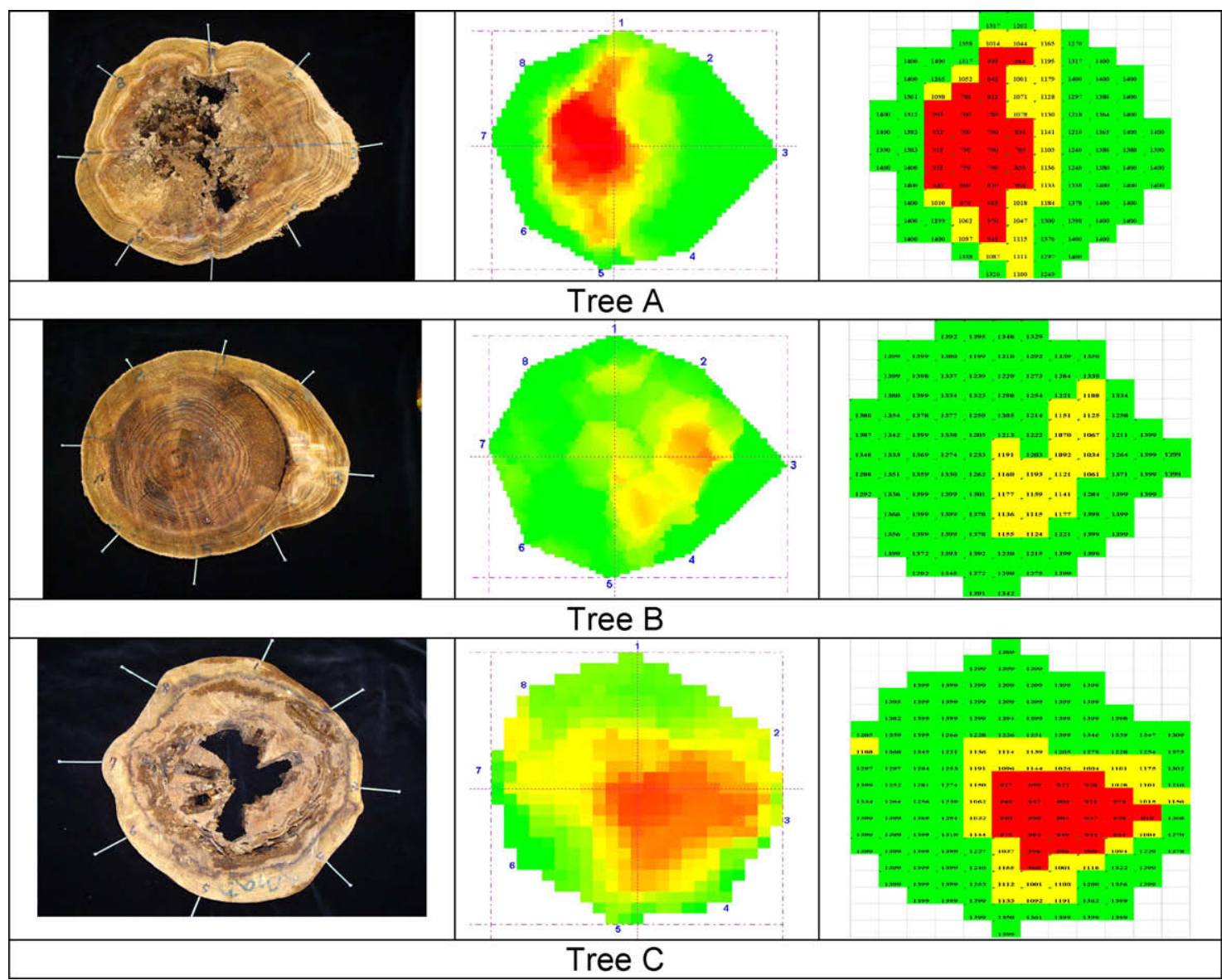

Fig. 8. Defect evaluation of trees by ultrasonic tomography (left, cross-section of trees; middle, two-dimensional tomogram; right, ultrasonic velocity).

Two-dimensional tomograms of side defect evaluation of discs by ultrasonic tomography are shown in Fig. 7. In this figure, more blue in the tomogram indicates a higher ultrasonic velocity. The highest ultrasonic velocity was $1900 \mathrm{~ms}^{-1}$. More pink in the tomogram indicates a lower ultrasonic velocity. The lowest ultrasonic velocity was $1400 \mathrm{~ms}^{-1}$. The color of the tomograms gradually changed from blue to light blue as the hole diameter gradually increased. The light blue area in the upper right part of the tomogram was detectable when the diameter of the hole was $3 \mathrm{~cm}$. The color of the tomograms turned green and red when the diameters of the holes were 6 and $11 \mathrm{~cm}$, respectively. Table 3 shows the correlations among the ultrasonic velocity obtained from ultrasonic tomography, the ratio of the hole-to-disc diameter, and the ratio of the hole-to-disc area. These results were significant at the 0.01 confidence level, and $r^{2}$ values of the regression analysis were $0.96-$ 0.99 .

\subsection{Field tests}

Fig. 8 shows the two-dimensional ultrasonic tomograms of trunk cros-sections $130 \mathrm{~cm}$ above the ground (at breast height) from trees A, B, and C. Trees A and C showed nearly central decay with a simple geometry, characterized by homogeneous wood degradation with a high mass loss (of about $32 \%$ and 59\%, respectively). The borders between the sound and decayed wood were clearly marked by the compartmentalization barrier. Tree B showed decay in the side of the trunk section with a mass loss of about $28 \%$. As a whole, defects of wood discs could be detected and evaluated by the two-dimensional ultrasonic tomography developed in our study.

\section{Conclusions}

Based on the experimental work conducted in this study, the following conclusions can be drawn.

1. The highest coefficient of determination $\left(r^{2}=0.94\right)$ was found between the residual disc diameter ratio and the ultrasonic velocity along path $\mathrm{D}$ (the virtual radial direction).

2. Strong correlations $\left(r^{2}=0.94\right.$ and 0.97$)$ between the drop in the relative ultrasonic velocity and the residual disc diameter ratio were observed in paths $C$ and $D$.

3. The ratio of ultrasonic velocity along paths $\mathrm{D}-\mathrm{B}\left(V_{\text {path } \mathrm{D}} / V_{\text {path B }}\right)$ decreased with increase in the ratio of the hole-to-disc area. However, $V_{\text {path D }} / V_{\text {path B values became diverse for specimens }}$ with a hole chiseled in the side area as the ratio of the hole-todisc area increased.

4. The difference in color mapping and ultrasonic velocity between the hole area and its surrounding area was obvious, and when the ratio of the hole area to disc area exceeded $2.8 \%$, the hole was detectable by ultrasonic tomography. Therefore, the location and size of the hole in the tree trunk section could be detected by ultrasonic tomography.

\section{Acknowledgments}

The authors wish to thank the Experimental Forest, College of Bio-Resources and Agriculture, National Taiwan University, for financial support. 


\section{References}

Anon, 2005. Arbotom Manual - Three-dimensional Impulse Tomograph for Examination of Trees and Timber. Rinntech, Germany.

Bauer, C., Kilbertus, G., Bucur, V., 1991. Technique ultrasonore de caractérisation du degré d'altération des bois de hêtre et de pin soumis à l'attaque de differents champignons. Holzforschung 45 (1), 41-46.

Biagi, E., Gatteschi, G., Masotti, L., Zanini, A., 1994. Tomografia ad ultrasuoni per la caratterizzazione difettologica del legno. Alta frequenza - Rivista dielettronica 6 (2), 48-57.

Bucur, V., 1995. Acoustics of Wood. CRC Press, Boca Raton, FL, 286 pp.

Comino, E., Socco, V., Martinis, R., Nicolotti, G., Sambuelli, L., 2000. Ultrasonic tomography for wood decay diagnosis. In: Backhaus, G.F., Balder, H., Idczak, E. (Eds.), International Symposium on Plant Health in Urban Horticulture, Braunschweig, Germany, 22-25 May 2000, p. 279.

Divos, F., Divos, P., 2005. Resolution of stress wave based acoustic tomography. In: Proceedings of the 14th International Symposium on Nondestructive Testing of Wood. Shaker Verlag, ISBN 3-8322-3949-9.

Habermehl, A., Ridder, H.W., Schmidt, S., 1986. Mobiles Computer-TomographieGreat zur Untersuchung ortsfester Objecte. Atomkernenergia-Kerntechnik 48 (2), 94-99.

Hailey, J.R., Morris, P.I., 1987. Application of Scanning and Imaging Technology to Assess Decay and Wood Quality in Logs and Standing Trees. Forintek Canada Corporation, Vancouver, BC.

Holoyen, S., Birkeland, R., 1987. Industrial methods for internal scanning of log defects: a program report on an ongoing project in Norway. In: Proceedings of the Second International Conference on Scanning Technology in Sawmilling Pap. X1-X18, San Francisco, CA.

Hoyle, R.J., Pellerin, R.F., 1978. Stress wave inspection of a wood structure. In: Proceedingsof the Fourth Symposium on Nondestructive Testing of Wood. Washington State University, Pullman, WA, pp. 33-45.

Hoyle Jr., R.J., Rutherford, P.S., 1987. In: Stress Wave Inspection of Bridge Timbers and Decking. Washington State University, Department of Civil and Environmental Engineering, Pullman, WA.

Lin, C.J., Chiu, C.M., Wang, S.Y., 2000. Application of ultrasound in detecting wood decay in squirrel-damaged standing trees of Luanta China fir. Taiwan Forest Science 15 (2), 267-279.
Mattheck, C.G., Bethge, K.A., 1993. Detection of decay in trees with the Metriguard Stress Wave Timer. Journal of Arboriculture 19 (6), 374-378.

McCracken, F.I., 1985. Using sound to detect decay in standing hardwood trees. In: Proceedings of the Fifth International Symposium on Nondestructive Testing of Wood; 9-11 September 1985; Pullman, WA. Washington State University, Pullman, WA, pp. 281-287.

Nolet, G., 1987. Seismic Tomography, with Applications in Global Seismology and Exploration Geophysics. Reidel, Boston, MA, 336 pp.

Oja, J., Grundberg, S., Gronlund, A., 2000. Predicting the strength of sawn products by xray scanning of logs: a preliminary study. Wood and Fiber Science 32 (2), 203-208.

Pellerin, R.F., Ross, R.J., 2002. Nondestructive Evaluation of Wood. Forest Products Society, Madison, WI.

Ross, R.J., Pellerin, R.F., 1994. Nondestructive Testing for Assessing Wood Members in Structures. A Review. Gen. Tech. Rep. FPL-GTR-70. US Department of Agriculture, Forest Service, Forest Products Laboratory, Madison, WI, 40 pp.

Rust, S., Göcke, L., 2000. PICUS sonic tomograph - a new device for nondestructive timber testing. In: Backhaus, G.F., Balder, H., Idczak, E. (Eds.), International Symposium on Plant Health in Urban Horticulture, Braunschweig, Germany, 22-25 May 2000, p. 300.

Sandoz, J.L., Benoit, Y., Demay, L, 2000. Wood testing using acousto-ultrasonic. In: Proceedings of the 12th International Symposium on Nondestructive Testing of Wood, 13-15 September 2000, University of Western Hungary, Sopron, Hungary. University of Western Hungary, pp. 97-104.

Stewart, R.R., 1991. Exploration of Seismic Tomography: Fundamentals. Society of Exploration Geophysicists, Course Notes, 190 pp.

Tomikawa, Y., Iwase, Y., Arita, K., Yamada, H., 1990. Nondestructive inspection of wooden poles using ultrasonic computed tomography. IEEE Transactions UFFC 33 (4), 354-358.

Wagner, F., Taylor, F., Ladd, D., 1989. Ultrafast CT scanning of logs for internal defects. In: Proceedings of the Seventh International Nondestructive Testing of Wood Symposium, Pullman WA, pp. 221-229.

Wilcox, W.W., 1988. Detection of early stages of wood decay with ultrasonic pulse velocity. Forest Products Journal 38 (5), 68-73.

Worthington, M.H., 1984. An introduction to geophysical tomography. First Break 2, 20-26.

Yamamoto, K., Sulaiman, O., Hashim, R., 1998. Nondestructive detection of heart rot on Acacia mangium trees in Malaysia. Forest Products Journal 48 (3), 83-86. 